\title{
Improving public services through open data: public toilets
}

1 Jo-Anne Bichard MSC

Research Fellow, Helen Hamlyn Centre for Design, Royal College of Art, London, UK
2 Gail Knight MA, MEng

Research Associate, Helen Hamlyn Centre for Design, Royal College of Art, London, UK
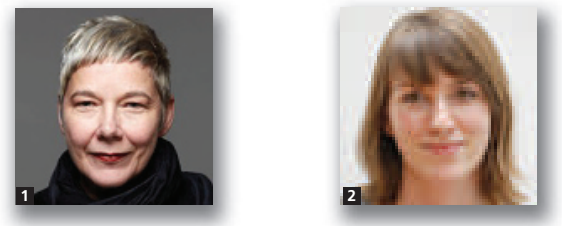

Everyone needs access to toilet facilities, but such provision outside the home can be hard to find. For those with common medical conditions and older people, this issue is critical for their continued independence, quality of life and wellbeing. In the UK there is no legal requirement for local authorities to provide 'public' toilets, nor is there a central source of information on provision, location, access and opening times. This paper presents a case study of The Great British Public Toilet Map - a web-based information service, derived from public-sector open data. The release of data held by the UK government, under open licence, could improve transparency, accountability and help to improve public services through the reuse of such data by designers, developers and public-led campaigns for more toilet provision.

\section{Introduction}

It is widely recognised that we live in an ageing society, with the UK over-50 s population set to increase by more than three million by 2020 (ONS, 2011). For many people, becoming incontinent with age is greatly feared, yet continence problems are extremely common in the adult population; it is estimated that between 30 and $60 \%$ of women over the age of 40 experience incontinence (Minassian et al., F08). Buckley et al. (2010) approximated that half as many men are also affected. Although not a direct result of ageing, studies show that urinary function and instances of incontinence can increase with age (Holm et al., 1995; Malone-Lee and Wahedna, 1993; Pfisterer et al., 2006). In addition, rising survival rates for bladder and bowel cancers may also raise awareness for the need of continence management. Reduced physical mobility coupled with reduced bladder and bowel function may cause concern when there is a need to find accessible facilities urgently and to use facilities more often. The issues facing the management of continence, including access to toilet facilities when away from home, are likely to become more prevalent with increasingly ageing populations.

It is proposed that, for essential quality of life in old age, the pleasures and challenges of life beyond the home should not be denied to older people (Holland et al., 2005). However in 2007, the UK charity Help the Aged (now known as Age UK) produced Nowhere to Go, a report on the perception of public toilet availability in the UK, and noted a marked decline in provision as being of central concern to older people, preventing many from leaving their homes as and when they liked (Help the Aged, 2007). Bichard and Hanson (2009) found that many older people managing continence actively limited the amount of time they were out of their homes for fear of having 'an accident' through there being no toilet provision or the provision being not easy to reach when needed urgently. Research has also identified that a perceived lack of adequate toilet provision can lead to the avoidance of travelling and using public amenities such as transport (Norton, 1982). Reduced mobility due to continence concerns and lack of toilet provision have been noted to increase a sense of social isolation and withdrawal from wider social activities (Wyman, 1994), including access to work environments (Lam et al., 1992). Atkins (2001) suggests that social withdrawal can lead to loss of self-esteem and therefore increase feelings of loneliness and depression. Such mental health concerns from self-enforced isolation due to continence management worries can only draw further on health and social service budgets.

\subsection{Providing public toilets for equality and diversity}

During the working day, access to toilet provision may increase as facilities in the 'private' sector (train and bus stations, department stores, cafes, etc.) are also available. In contrast, at 
close of business, many city centres offer no suitable toilet provision, effectively denying many older and disabled people access to the space and amenities of the evening economy including theatres and cinemas, as well as education and learning opportunities. Greed (2003) found that many women 'journey plan' based on toilet provision and the lack of widely available toilet provision effectively holds people by 'the bladder's leash', restricting movement to areas in which toilet provision is known and trusted (Kitchen and Law, 2001).

While it is currently recognised that there is a decrease in UK public toilet provision, innovative solutions have aimed to meet the toileting needs of public. The automatic public convenience (APC or 'superloo') is a self-cleaning standalone unit that caters to a single user and operates a cleaning cycle after each use. However, the APC has not proved popular with users, especially older women (Hanson et al., 2007). Other solutions, such as the Urilift - a three-space urinal facility that is stored underground during the day and raised in the evening - provide facilities for night-time urination needs. However, due to the nature of the design (as a urinal unit), it can be considered that such solutions do not cater to the wider evening toilet provision of the public, including men with disabilities, men who observe hygiene practices as faith observances and women of all ages and abilities.

Since 2004, the Disability Discrimination Act (DDA) has recognised loss of continence as a disabling condition. In order to meet the requirements of part three of the DDA, which focuses on access to goods and services, many providers focused on the provision of an accessible cubicle to be seen to meet the needs of disabled people. The wider need for publicly accessible toilets to meet the requirements of people with continence concerns failed to be realised, with many public toilets closing due to financial constraints of maintenance and perceived inflationary costs in meeting access standards (Hanson et al., 2007).

Current UK toilet provision is sporadic. Some areas operate well-signed facilities that can be easily located, are well maintained and fully accessible, while other areas of the country have limited provision that is hard to locate or no provision at all (Knight and Bichard, 2011a).

\subsection{The case for open data}

In 2011, the UK government published its Open Public Services White Paper, which emphasised a commitment to incorporate the use of open data in delivering public services in order to support individuals to hold service providers to account and to make more informed choices (Cabinet Office, 2011). Garbett et al. (2011) noted that many governments are now committed to releasing public records, suggesting that 'the open data movement promises to improve transparency of government services and improve the ability of citizens to scrutinize the efficiency of the Government'.

Open data refers to information (data) that is made available by organisations, including those in the public sector, that can be freely used, reused and redistributed by members of the public. Open data is not only available but also offers the opportunity to collate, combine and enhance information to provide a broader picture of public services and therefore enable communities to make informed decisions about the areas they live in (Garbett et al., 2011).

O'Reilly (2010) argues that the development of the World Wide Web and Web 2.0 has offered new methods 'for harnessing creativity of people in groups' as well as fostering new models of collaborative working. The increase of new business models to work within these dynamic environments has not gone unnoticed by governments who see the power of Web 2.0 technologies, such as social media, not only of benefit to economies but also to help get them elected. O'Reilly suggests this has led to a movement called Government 2.0 that, in the USA, is envisaged as a government 'stripped down to its core, rediscovered and reimagined' using technology 'especially the collaborative technologies at the heart of Web 2.0 - to better solve collective problems at a city, state, national and international level'.

Within the context of the UK, a report by the Office of Public Sector Information states that 'the UK public sector is a source of rich, high quality and sought after data' (OPSI, 2007). However, the report recognised that this information is 'often trapped by poor data structures, locked up in legacy data formats or in fragmented databases'. The challenge, as identified by Shadbolt (2010) is to ensure that information is published timely and in a reusable form. Garbett et al. (2011) argue that the presentation of data is crucial for the success of the open data movement, not only to encourage wider use but also to inspire innovation by encouraging different interpretations of the dataset.

\section{Challenging environmental barriers to continence}

Between November 2008 and April 2012 a multi-disciplinary research team led by Brunel University and comprising researchers from the Royal College of Art and the Universities of Sheffield, Manchester and the West of England, Bristol Urological Institute and Dalarna University in Sweden investigated the complexities of continence management for an ageing population. The project 'Tackling ageing continence through theory tools and technology (TACT3)' is funded by the New Dynamics of Ageing programme and is 'a seven year multidisciplinary initiative with the ultimate aim of improving the quality of life of older people. The programme is a unique 
collaboration between all of the UK's research councils and is the largest and most ambitious research programme on ageing ever mounted in the UK' (www.newdynamics.group.shef.ac. uk). Through four work packages, TACT3 has explored the effect of continence through the development of user-requested assistive technologies ('smart underwear' and odour-sensor devices), the National Health Service continence care delivery from both the perspective of the service user (patient) and the service provider (medical staff), and the management of continence when outside the home. This latter work package was undertaken by the authors. Working under the title 'Challenging environmental barriers to continence' the work package focused on how the provision of 'away from home' toilets can be maximised to meet the demands of an ageing population, but within the realistic remit of those providing toilet facilities.

\section{Inclusive design research in public toilet provision}

\subsection{Public perceptions of toilet provision}

Greed (2011: p. 108) suggests that inclusive urban design would ideally be an over arching principle, and indistinguishable from regular 'urban design', not a compensatory add-on, resulting in enabling environments'.

The Helen Hamlyn Centre for Design at the Royal College of Art, where the authors are based, focuses its design research on inclusive and people-centred processes and methodologies. Within the Challenging environmental barriers to continence work package, the authors identified two user groups

- the public, as users of public toilet facilities

providers, who manage and maintain publicly accessible toilets.

Previous research (Greed, 2003) identified these two groups as being in conflict with regard to the demands of provision and the service provided. The work package was thus designed to bring together these two distinct groups of users and identify commonalities from which design solutions could be developed.

Working from an inclusive methodology, a key driver in the first phase of the work package was to identify, in collaboration with members of the public as research participants, the barriers that prevented equity of access to toilet provision. Following an initial consultation with an older people's reference group, it was suggested by the participants that access to toilet facilities when away from home affects people of all ages. Consequently, the research was redesigned to represent people of all ages, as well as a diverse range of abilities, ethnicities and experiences, in particular those with continence-related concerns. Interviews were conducted with 101 people in each age bracket from the parents/carers of newborn babies to those aged over 90 . The interviews revealed the following three key areas that the research participants considered to be the main barriers that prevented them from using toilets safely and with comfort and dignity.

Hygiene: toilet facilities have to be clean; toilets perceived as dirty are avoided.

- Function: facilities have to be accessible and in good working order; toilets that are difficult to access or use with ease are also avoided (this included APCs).

- Information: users need to find a toilet that suits their particular circumstances and personal preferences.

To represent the needs and experiences of the interviewees, the researchers developed a series of four 'personas' to help communicate user needs to providers in the second phase of the project. The personas included the following.

A 26-year-old female trainee teacher with irritable bowel syndrome; this persona represented the need to access toilet facilities urgently as not being necessarily an age-related issue.

A 38-year-old male self-employed photographer with three young children represented the issues facing men with young children, including access to baby changing and family provision, if not accompanied by a female partner.

- A recently retired, 60-year-old woman who cares for her mother and who is herself beginning to take age-related medication that, as a side-effect, increases the frequency with which she needs to access a toilet.

- An 82-year-old man who uses a walking aid and is concerned with safe, accessible toilet provision in his local urban high street.

\subsection{Provider perceptions of toilet provision}

Greed (2003) identified UK public toilet provision as being 'fragmented' between a number of different service providers. This includes not only those in the public sector (standalone local authority facilities), but also provision operated by private organisations such as toilets found in train and bus stations and shopping centres. Even within local authority provision there is often a 'fractured' service, with facilities operated by different departments within the authority such as parks and recreation and environmental services. Further confusion regarding provision has evolved through the introduction of community toilet schemes. These schemes act as partnerships between local authorities and local businesses in which the authority pays an annual premium to cover costs to the business in making their toilets available to noncustomers. Greed (2011: p. 114) has critiqued such schemes as uninviting to women who may be 'wary' of using community 
provision operated by a bar or public house. In essence, Greed's critique only focuses on the issue of gender and access to specific sites. Research undertaken by Hanson et al. (2007) found that many women prefer to use 'private' provision as it is generally thought to be cleaner and therefore more hygienic. Encompassing the nature of such varied types of provision, the research adopted the term 'publicly accessible toilets' to include those operated by both the public and private sector.

To understand the challenges faced by a variety of providers, the researchers conducted face-to-face interviews with 20 professionals involved in toilet provision. These included: architects specialising in shopping centres and urban planning; police officers involved in community design decision making; local authority officers from departments of waste services, park management and planning; public toilet manufacturers; department store internal architects; train station managers; and organisers for the 2012 London Olympics. The providers cited key barriers to provision that conflicted with user requirements. These included the difficulties and expense of keeping toilets to the standard expected by the public while also deterring non-toileting behaviour such as vandalism, graffiti, illegal drug use and public sex activities.

\subsection{Identifying shared solutions for users and providers}

When examining the experiences detailed by both user groups (members of the public and providers), the researchers noted that a key but often overlooked area of provision concerned information about the facilities on offer, including where toilets were located, their opening hours and access options including level access, accessible (disabled) cubicle, baby changing and family provision. For members of the public managing continence concerns, accurate information on provision was deemed essential, with dire and upsetting consequences should poor information be given such as toilets not being open or inaccessible to the individual. In contrast, providers faced the challenge of keeping information up-todate and accurate within reasonable operational budgets. Providers and associated professionals recognised that providing accurate information could increase usage and possibly deter some of the non-toileting behaviours taking place in empty and infrequently used facilities that were costly to manage and mend.

\section{Creating information on public toilet provision with open data}

\subsection{Information collation}

Currently, there is no centrally collated information, inventory or database on UK public toilet provision. As with the fragmentation of service delivery, there are 406 district, unitary authority and borough councils in Great Britain that hold pieces of the information puzzle. The situation is even more complicated when privately provided yet publicly accessible toilets are also considered. There has been a lack of joined-up thinking in bringing the information together.

To understand the level of fractured provision, the researchers undertook a case study of publicly accessible toilets in the borough of Wandsworth in southwest London. The research identified 9 public toilets (all APC models) yet a total of 112 publicly accessible toilets, including parks, transport terminals and the borough's community toilet scheme. As shown in Figure 1, provision consisted of

\section{APCs (superloos)}

10 in council buildings (in libraries and the Town Hall)

5 in parks and cemeteries

11 'Open London' members (a toilet scheme run by the Mayor of London) and shopping centres

- 3 in train stations

74 in shops, cafés, pubs and bars (community toilet scheme).

However, the researchers found that a central problem with the provision offered by the local authority in Wandsworth was that many people were unaware of the majority of facilities and did not know which toilets, especially those in businesses, they could use without have to make a purchase.

In particular, franchised high street chains would have one branch in one area permitting access with another branch in another area restricting access to customers only. In addition, while Wandsworth Council provided information online about the toilet provision it managed (including membership and location of businesses signed up to the community toilet scheme), neither the council nor any other body had information on all of the publicly accessible toilets available in the borough.

\subsection{Using open data for public toilet provision}

Both providers and members of the public recognise that information on public toilets - including where they are located, opening times and access provisions - is essential for providing an efficient service and for people managing continence concerns.

This research identified that a significant step in providing information on public toilet provision would be the development of a national map and open dataset. The dataset in particular would allow people to create further local, regional and customisable maps and smartphone applications, and integrate the information into other maps and applications. Yet one of the key barriers to developing such a web-based dataset was the fractured nature of provision with so many local authorities and other bodies responsible for publicly accessible toilets. 


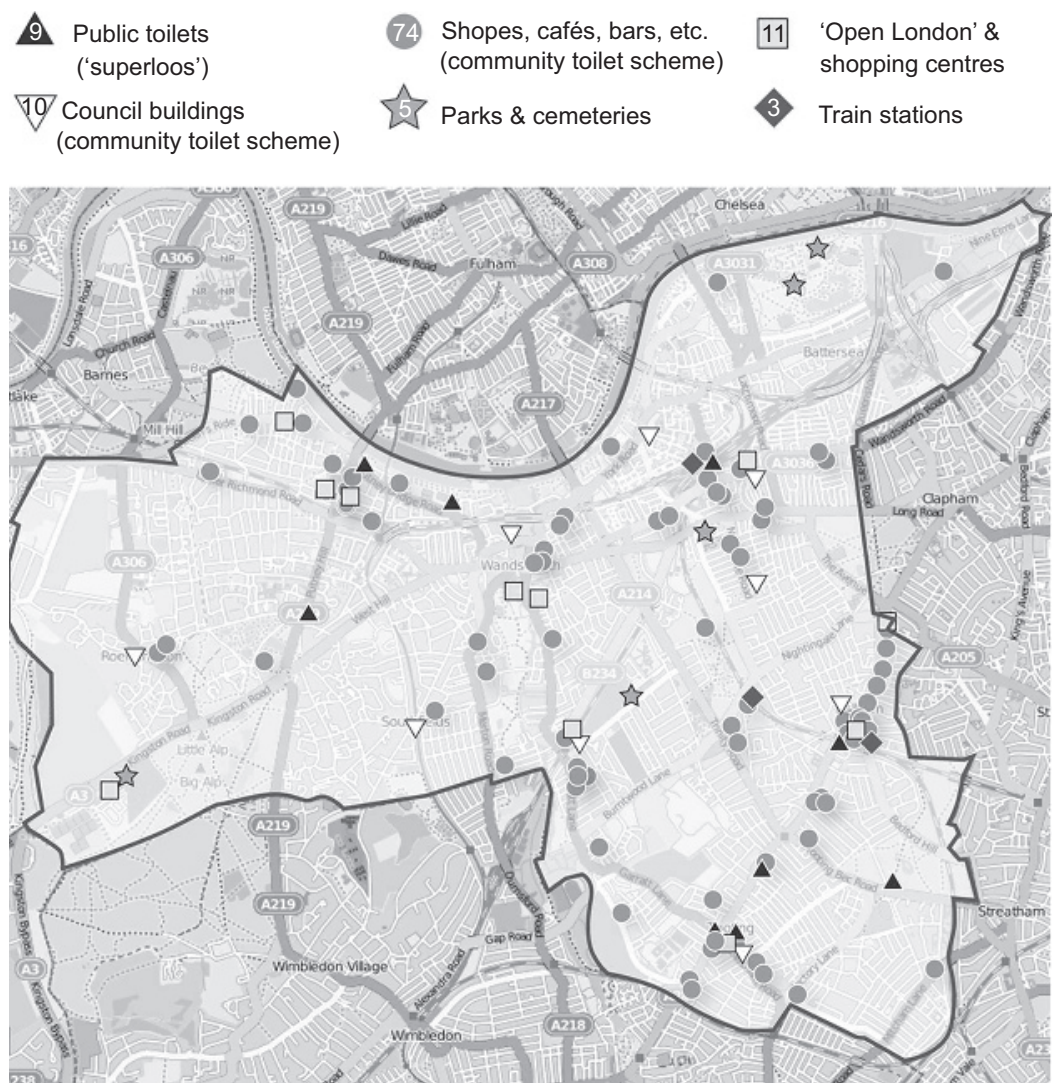

Figure 1. Map of the 112 publicly accessible toilets in the London Borough of Wandsworth (map image (c) Open Street Map Contributors, CC-BY-SA)

Many local authorities do provide information on their toilet provision through their websites. However, council websites may not be the first place that people visit when they need to find a public toilet - particularly when they are already out and about. Furthermore, a visitor to an area is unlikely to know which council area they are in or which levels of two- or threetier council is responsible for the local toilet provision.

Based on the user engagement undertaken during the project, the researchers felt that national open data on current public toilet provision was an essential development. In July 2010, the authors contacted data.gov.uk, the government's central website for open data, to confirm that no central body collected or provided information about the UK's public toilets. One source of national location data is held and displayed on Ordnance Survey (OS) maps, but this information is limited to location data for physical toilet buildings with no additional information such as opening hours or the range of facilities provided. In addition, such data do not include the growing numbers of community toilet schemes. The research also found that the OS data are actually owned by Point X, a third-party company invested in jointly by OS and Landmark Information Group. While OS does provide some of its location information as open data (particularly if it is for 'public good'), opening up public toilet data would be impossible as it would be in direct competition with the third-party Point X dataset.

As of July 2010, the only open data on public toilet provision available on data.gov.uk were for the London Borough of Brent. Previous work in local open data instigated by 'Openly Local' - a project to 'develop an open and unified way of accessing Local Government information' (http://openlylocal. $\mathrm{com} /$ ) - requested that councils publish local election data as open data. According to data.gov.uk (2010), there 12 barriers making the task of opening up data at a local government level difficult, including 'lack of "corporate" awareness/understanding of open data', 'lack of even basic web skills at some councils' and 'many councils lacking web publishing resources', sometimes with an annual budget of $£ 0$. Openly Local also created a scoreboard of councils (Openly Local, 2012) to show how committed to open data each council was, based on whether 
they had a dedicated open data webpage or section where data could be downloaded. Based on this scoreboard, the authors of this paper began contacting 'open' councils to request that they include open public toilet data in their datasets. By July 2011, around a quarter of those contacted responded positively by creating or planning to create the data (Figure 2). To date, the researchers have contacted approximately 100 councils and are aware of 21 sets of open data about public toilets that have been published by local authorities.

The researchers used the social media tool Twitter to engage with local government officers, civil servants and developers that make up the online open data community. Through Twitter, interested parties could be identified by tweeting and following the open data hashtag (\#opendata). Further online engagement was developed through 'Public Toilets and...' blog (http://gailknight.wordpress.com/) where Knight described the process and problems the project encountered and appealed to the community for feedback, ideas and solutions.

The researchers also assisted in a Greater London Authority (GLA) study of public toilets in London and participated in a GLA-led collaborative document to develop an open data standard for public toilets (London Assembly, 2011). This standard received contributions from experts in public toilets, accessibility and computer programming. The development and future adoption of a data standard for public toilet provision is vital for the longevity of the project, so that the data content and data format that each council provides is complete, comparable and consistent.

\section{The Great British Public Toilet Map}

In order to both collate and promote public toilet open data, the researchers designed an online map that would display toilet locations and information where available. Due to the sheer number of local authorities involved it was decided that the website should be for a limited geographical area. This would make it easier to work closely with those councils within the area that had little or no understanding of open data. In light of the GLA standard, the number of people visiting the area and the three datasets that were already available, the researchers focused on the 33 boroughs within Greater London. The aim of the map was to demonstrate the usefulness of open data and to highlight which councils do and do not provide public toilet open data, in order to appeal to the competitive or collaborative instincts of councils that were not providing open data. The website is called The Great British Public Toilet Map (Figure 3) (http://greatbritishpublictoiletmap.rca.ac.uk/).

As well as an information portal, The Great British Public Toilet Map also acts as a public participation and campaigning site. If a council has not yet published their open data on toilet provision, the website provides a customisable online letter that users can send to the relevant council. The letter explains the

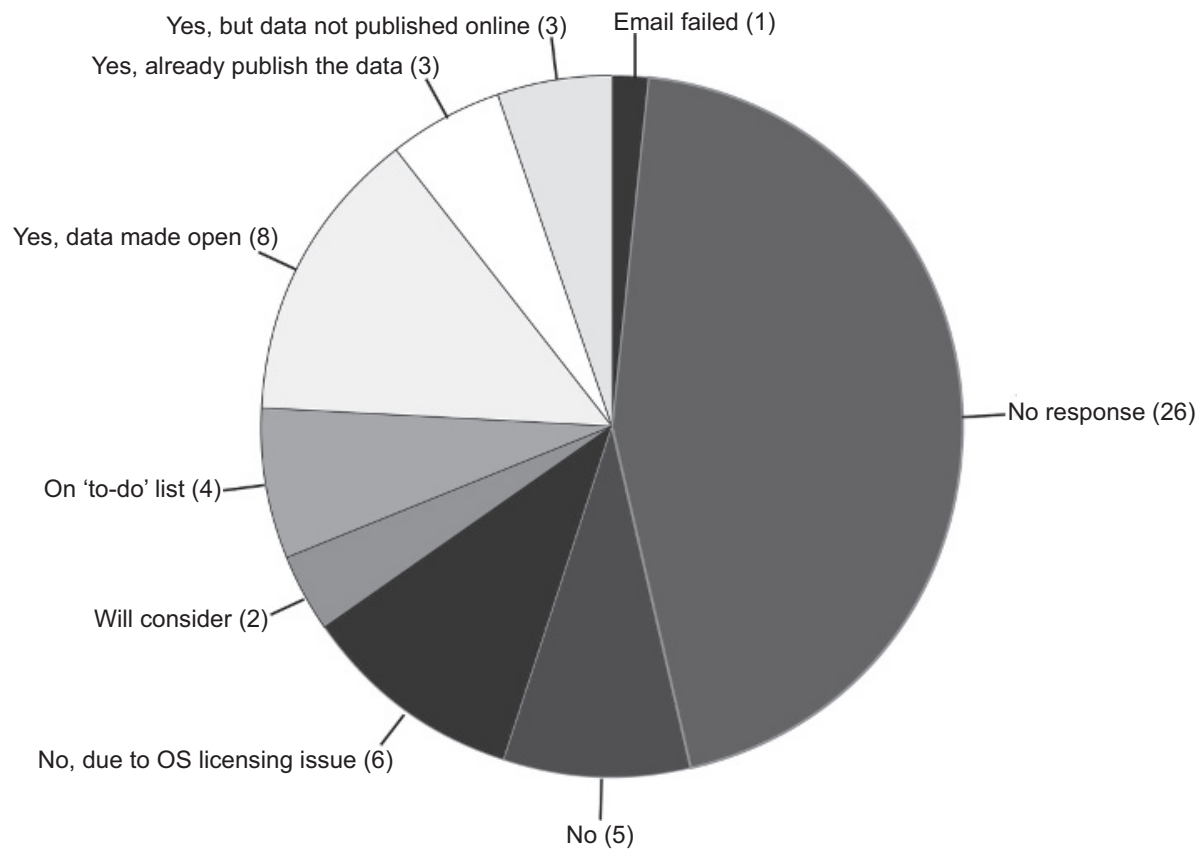

Figure 2. Council response rate to public toilet open data request, July 2011 (from 58 'open' councils) 


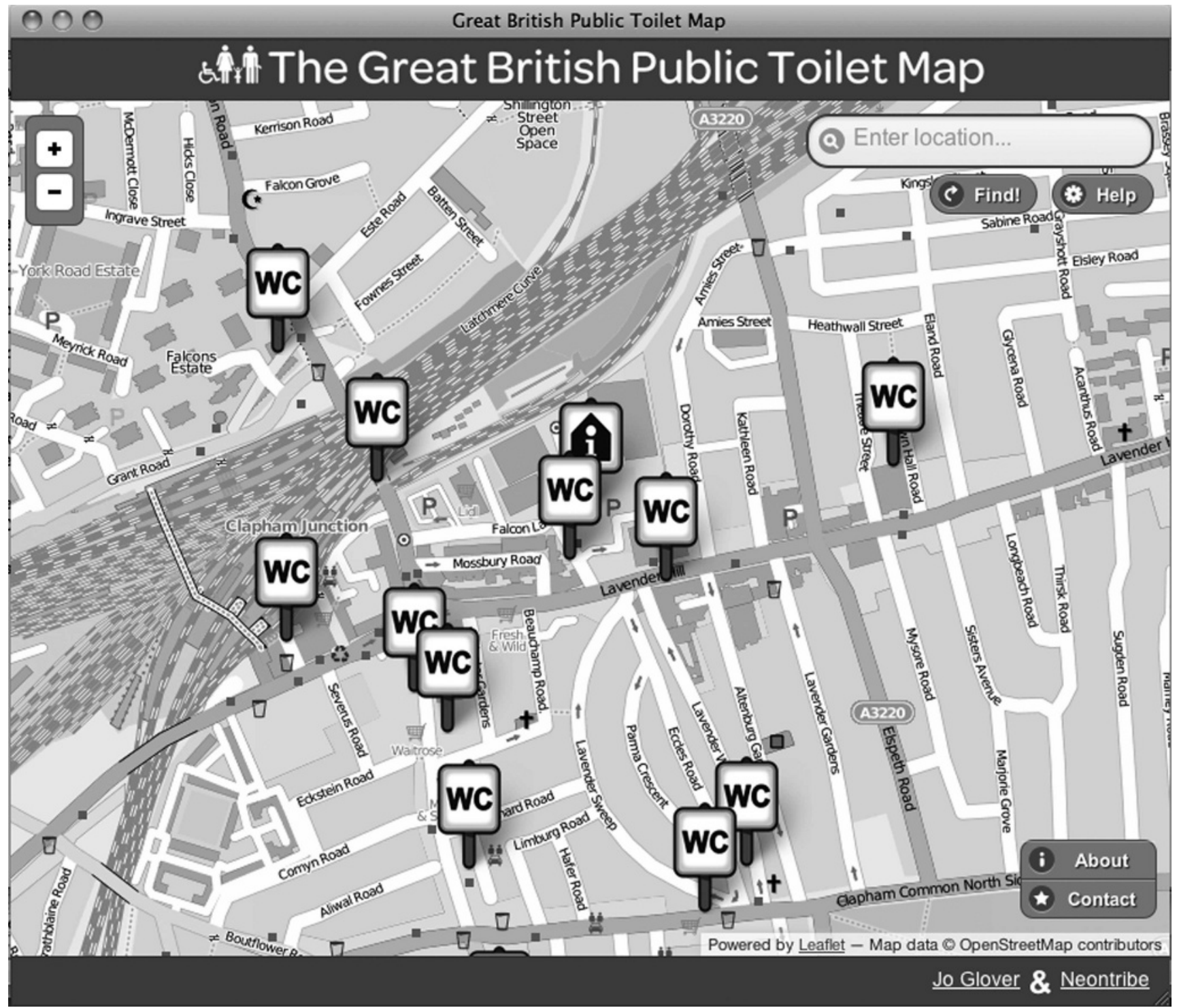

Figure 3. Screenshot of The Great British Public Toilet Map

idea of open data, encourages the council to provide their own and explains why this information will be useful to the sender.

The London version of the toilet map went live in September 2011. This map is the key deliverable for the challenging environmental barriers work package as part of the TACT3 project. At the beginning of the research project, only one of London's 33 boroughs published public toilet open data. Prior to the site launch, the researchers successfully requested that data be published by four other councils and three more have published data in the six months since launch. Thirteen further councils have been contacted by members of the public through the website.
There are several barriers to further council publication of public toilet open data. These are

a lack of understanding of open data by the person responsible for public toilets

a lack of capability at some councils to provide online open data

- each council using different dataset formats and each requiring bespoke coding in order to be integrated into the website

restrictions on councils' publication of latitude/longitude coordinates of public toilets as open data due to OS licensing 
lack of understanding of the benefits of collated open data rather than a map on each council's own website.

The researchers have identified how these barriers could be addressed. The issues around understanding of open data, the capability to provide open data and format consistency could be solved by creating an online interface where council officers with basic computer skills could enter their public toilet information directly into the website. The council officer could also locate these facilities on an online map, circumnavigating the need to publish latitude and longitude coordinates derived by OS. The council officer could update the information at any time, with immediate effect on the map display. All data could be output as open data for other developers and members of the public to download and use. The development of such an interface would, however, require further investment.

A similar map was initiated by the Department of Health and Ageing in Australia in 2001 (www.toiletmap.gov.au) as part of the country's National Continence Management Strategy. The Australian Public Toilet Map currently contains over 15000 publicly accessible toilet facilities with data supplied by over 1000 organisations including councils. The website attracts 100000 visitors per month, with a rise of $700 \%$ in visitor numbers since 2004. The data that populates the map is provided as open data to encourage innovative smartphone solutions such as toilet finder applications. The success of the Australian map suggests that this is an area worthy of consideration for investment by the UK government at a national level.

\section{Conclusion}

The Challenging environmental barriers work package, as part of the collaborative research project Tackling ageing continence through theory tools and technology (TACT3), worked with members of the public and providers of publicly accessible toilets to understand some of the challenges faced by user groups in accessing and providing toilet facilities. A key finding of this work involved the need for accurate information to be provided and for this to be done in a cost-effective way. The generation of open data was identified by the research team as an ideal way to provide information on public toilet provision that incorporated not only location details but also opening times and the range of facilities on offer (including accessible cubicles and baby changing provision). Generating open data on UK public toilet provision is being both encouraged and displayed through The Great British Public Toilet Map website. It is the authors' hope that the map will continue to be populated with open data on toilet provision by local councils and will eventually be populated by open data produced by private providers of publicly accessible toilets, such as train and bus companies who provide facilities within the transport infrastructure. In addition, shopping centres, department stores, service stations and other businesses offering publicly accessible toilets could contribute detailed information on their own toilet facilities. This information is considered vital for an ageing population who may be managing continence concerns and who may find that their movement within cities and surrounding areas is curtailed due to the need to access toilets frequently and with ease.

However, there are a number of barriers that prevent councils from providing public toilet open data. These include a lack of understanding of what open data is, how it is created and what format and standard to adhere to. The researchers propose a possible solution by creating an interface to aid local government workers to input information that can be output as open data. This presents an opportunity for central government to create such an interface to carry forward its agenda of transparency within local government services.

Knight and Bichard (2011b) suggest that there are many toilets on UK high streets that are available to members of the public. However, with the remit that publicly accessible toilets might be 'for customers only', there lacks a general 'right of access' to this provision. They question if there is a need for more public toilets or a need for more access to existing provision.

Rather than limiting provision to falling numbers of counciloperated facilities, collated data about all publicly accessible toilets could help address future demands, making better use of natural resources and collectively meeting the needs of all members of public who rely on toilet facilities.

\section{REFERENCES}

Atkins WS (2001) Older People: Their Transport Needs and Requirements. Department of Transport, Local Government \& the Regions, London, UK.

Bichard J and Hanson J (2009) Inclusive design of 'away from home' toilets. In Designing Sustainable Cities (Cooper R, Evans G and Boyko C (eds)). Wiley-Blackwell, Oxford, UK, pp. 86-108.

Buckley BS and Lapitan MC (2010) Prevalence of urinary incontinence in men, women, and children: current evidence: findings of the Fourth International Consultation on Incontinence. Urology 76(2): 265-270.

Cabinet Office (2011) Open Public Services White Paper. The Stationery Office, London, UK.

data.gov.uk (2010) Publishing Local Open Data - Important Lessons from the Open Election Data Project. See http:// data.gov.uk/blog/publishing-local-open-data-importantlessons-open-election-data-project (accessed 13/03/2012).

Garbett A, Linehan C, Kirman B, Wardman J and Lawson S (2011) Using social media to drive public engagement with open data. Digital Engagement 11, Newcastle, UK. University of Dundee, Dundee, UK. See http://de2011.computing. dundee.ac.uk/?page_id=211/ (accessed 19/03/2012). 
Greed C (2003) Inclusive Urban Design: Public Toilets. Architectural Press, Oxford, UK

Greed C (2011) Planning for sustainable urban areas or everyday life and inclusion. Urban Design and Planning 164(2): 107-119.

Hanson J, Bichard J and Greed C (2007) The Accessible Toilet Resource. UCL, London, UK. See http://eprints.ucl.ac.uk/ 4847/ (accessed 15/06/2012).

Help the Aged (2007) Nowhere to Go; Public Toilet Provision in the UK. Help the Aged, London, UK.

Holland C, Kellaher L, Peace S et al. (2005) Getting out and about. In Understanding Quality of Life in Old Age (Walker A (ed.). Open University Press, Maidenhead, UK, pp. 49 63.

Holm NR, Horn T and Hald T (1995) Detrusor in ageing and obstruction. Scandinavian Journal of Urology and Nephrology 29(1): 45-49.

Kitchen R and Law R (2001) The socio-spatial construction of (in)accessible public toilets. Urban Studies 38(2): 287-298.

Knight G and Bichard J (2011a) Finding public toilets through applications and open data. Proceedings of Include 2011: The Role of Inclusive Design in Making Social Innovation Happen. Royal College of Art, London, UK.

Knight G and Bichard J (2011b) Publicly Accessible Toilets: An Inclusive Design Guide. Helen Hamlyn Centre for Design, Royal College of Art, London, UK.

Lam GW, Foldspang A, Elving LB and Mommsen S (1992) Social context, social abstention and problem recognition correlated to adult female urinary incontinence. Danish Medical Bulletin 39(6): 565-570.

London Assembly (2011) Public Toilets in London. See http:// www.london.gov.uk/publication/public-toilets-london (accessed 19/03/2012).
Malone-Lee JG and Wahedna I (1993) Characterisation of detrusor contractile function in relation to old age. British Journal of Urology 72(6): 873-880.

Minassian VA, Stewart WF and Craig Wood G (2008) Urinary incontinence in women: variation in prevalence estimates and risk factors. Obstetrics \& Gynecology 111(2), Pt 1: 324 331.

Norton C (1982) The effects of urinary incontinence in women. International Rehabilitation Medicine 4(1): 9-14.

ONS (Office of National Statistics) (2011) 2010-based National Population Projections. See http://www.ons.gov.uk/ons/ publications/re-reference-tables.html?edition $=\mathrm{tcm} \% 3 \mathrm{~A} 77$ 229866 (accessed 09/03/2012).

OPSI (Office of Public Sector Information) (2007) The United Kingdom Implementation of the European Directive on Reuse of Public Sector Information - The First Two Years. See www.opsi.gov.uk/advice/psi-regulations/ukimplementation-first-years.pdf (accessed 03/03/2012).

Openly Local (2012) UK Councils Open Data Scoreboard. See http://openlylocal.com/councils/open (accessed 19/03/ 2012).

O'Reilly T (2010) Government as a platform. Innovations 6(1): 13-40.

Pfisterer M, Griffiths D, Schaefer W and Resnick N (2006) The effect of age on lower urinary tract function: a study in women. Journal of the American Geriatrics Society 54(3): 405-412.

Shadbolt N (2010) Why Open Government? Data Lessons from data.gov.uk. See http://eprints.ecs.soton.ac.uk/21648/ (accessed 03/03/2012).

Wyman JF (1994) The psychiatric and emotional impact of female pelvic floor dysfunction. Current Opinion in Obstetrics Gynaecology 6(4): 336-337.

\section{WHAT DO YOU THINK?}

To discuss this paper, please email up to 500 words to the editor at journals@ice.org.uk. Your contribution will be forwarded to the author(s) for a reply and, if considered appropriate by the editorial panel, will be published as discussion in a future issue of the journal.

Proceedings journals rely entirely on contributions sent in by civil engineering professionals, academics and students. Papers should be $2000-5000$ words long (briefing papers should be 1000-2000 words long), with adequate illustrations and references. You can submit your paper online via www.icevirtuallibrary.com/content/journals, where you will also find detailed author guidelines. 